\title{
National workshop for health research prioritization in Jordan ${ }^{1}$
}

Citation: National workshop for health research prioritization in Jordan. East Mediterr Health J.2021;27(11):1125-1126. https://doi.org/10.26719/2021.27.11.1125 Copyright (C) World Health Organization (WHO) 2021. Open Access. Some rights reserved. This work is available under the CC BY-NC-SA 3.0 IGO license (https://creativecommons.org/licenses/by-nc-sa/3.o/igo).

\section{Introduction}

The Eastern Mediterranean Region (EMR) is confronting unprecedented challenges, exacerbated by demographic and epidemiologic changes, large burden of noncommunicable and communicable diseases, increasing health care expenditure, as well as the effects of chronic emergencies, social conflicts and population movements (1-3). Research for health is essential for generating evidence that can contribute to health improvement, economic growth and equity. Health research priority-setting is one the four pillars of WHO's strategy on research for health (4). Research prioritization is crucial, as it assists in best utilization of available resources in areas that maximize the research impact on population health. To achieve this goal, in September 2020, WHO published guidance on adopting a systematic approach to undertaking research priority setting (5). The systemic approach outlined in the guidance suggests four phases for health research prioritization: Plan, Implement, Publish and Evaluate (PIPE). Jordan was the first country in the Region to conduct a national health research priority-setting exercise using the WHO guidance. A workshop was held virtually using the interactive Zoom platform on 15 February 2021. It was attended by more than 50 participants from Jordan's public sector and from different national and international organizations. The main aim of the workshop was to enhance research for health through research mapping activities and prioritizing a list of research areas for Jordan.

Objectives of the workshop were to: review the national health research priority-setting exercise in Jordan; develop a short list of research statements for each of the three research areas from pre-developed long lists, through voting on two criteria: public health importance and feasibility.

\section{Summary of discussions}

A nominal group technique (NGT) methodology was used for the priority-setting exercise. NGT uses small group discussion to generate a list of research options, then the facilitator asks the participants to independent- ly prioritize the ideas by voting, rating or ranking. The facilitator summarizes the scores to determine the priorities. In an agreement between WHO and the Ministry of Health, three main research areas were chosen according to national strategies, plans and prioritized action plans. These were: health systems, including universal health coverage and resource management; health services, including digital health and health migration, and COVID-19 response, including public health surveillance. Ministry of Health experts, with the support of WHO, provided a long list of research statements covering these three identified main research areas. During the workshop, participants worked in three groups to review the long list of research statements. Each participant privately voted on each research statement on a scale of $0-9$, based on the two criteria: 1) public health importance; and 2) feasibility (a composite criterion covering technical, financial and logistic feasibility). An average score was calculated by the facilitators, ranking the research statements. All scores were recorded by facilitators on a dedicated spreadsheet for each group. An average score for each research statement was calculated which was ranked by sorting from the largest to smallest of average scores. The three parallel groups successfully prioritized the long list of research statements and provided short lists of 10-15 research statements. The short lists of health research priorities were subsequently shared with participants for further comments/ suggestions, before endorsement and dissemination to stakeholders in Jordan. This would concludes the first two steps in the WHO guide for national health research prioritization exercises (the planning and implementation phases).

\section{Recommendations}

The Jordan Ministry of Health and WHO country office will collaborate to formalize a national technical working group, which will be tasked to oversee the implementation of the outcomes of the national workshop. Other actions will include developing a timeline and a monitoring and evaluation plan, which will also be spearheaded by the Ministry of Health.

\footnotetext{
This summary is extracted from the report on the National workshop on health research in Jordan, 15 Feb 2021 (https://applications.emro.who.int/docs/WHOEMRPCo49Eeng.pdf?ua $=1$ )
} 


\section{References}

1. World Health Organization Regional Office for the Eastern Mediterranean (WHO/EMRO). EMR Vision 2023 Eastern Mediterranean Region. Cairo: WHO/EMRO; 2019 (http://www.emro.who.int/about-who/vision2023/vision-2023.html).

2. Al-Mandhari A. Public health in the Eastern Mediterranean Region: profound challenges, huge opportunities. Lancet. 2019 Sep 21;394(10203):992-993. DOI: 10.1016/So140-6736(19)32138-5.

3. Al-Mandhari A. Achieving "Health for All by All" in the Eastern Mediterranean Region. East Mediterr Health J. 2019 Oct 13;25(9):595-596. DOI: 10.26719/2019.25.9.595

4. World Health Organization. WHO strategy on research for health. Geneva: World Health Organization; 2012 https://apps.who. int/iris/bitstream/handle/10665/77935/9789241503259_eng.pdf;jsessionid=D92838E04CE129646D43DEoF267168C5?sequence=1

5. World Health Organization. A systematic approach for undertaking a research priority-setting exercise. Guidance for WHO staff. Geneva: World Health Organization; 2020 https://apps.who.int/iris/bitstream/handle/10665/334408/9789240009622-eng. pdf? sequence $=1$ \&isAllowed $=\mathrm{y}$ 